University of Wollongong

Research Online

Faculty of Social Sciences - Papers (Archive) Faculty of Arts, Social Sciences \& Humanities

$1-1-2016$

Preparing to cross the research proposal threshold: A case study of two international doctoral students

Meeta Chatterjee

University of Wollongong, meeta@uow.edu.au

Wendy S. Nielsen

University of Wollongong, wnielsen@uow.edu.au

Follow this and additional works at: https://ro.uow.edu.au/sspapers

Part of the Education Commons, and the Social and Behavioral Sciences Commons

Research Online is the open access institutional repository for the University of Wollongong. For further information contact the UOW Library: research-pubs@uow.edu.au 


\title{
Preparing to cross the research proposal threshold: A case study of two international doctoral students
}

\author{
Abstract \\ This paper presents a study of two international doctoral students' perspectives on preparing to formally \\ present the thesis proposal, which we conceptualise as a threshold in the PhD journey. They participated \\ in a thesis writing group (TWG) that aimed to support international doctoral students to develop aspects \\ of their scholarship in the early stages of their candidature. The case students reported feeling 'stuck' \\ before joining the TWG run by the authors. After the writing group experience, they reported that they had \\ gained confidence and developed the skills and knowledge required to prepare for their proposal \\ presentation. Their perspectives were gathered through semi-structured interviews that were analysed \\ using the conceptual framework of threshold concepts for doctoral learning. This small-scale study \\ suggests that the collegial support provided by a TWG can be a powerful pedagogy enabling doctoral \\ scholars to confidently negotiate crossing the thesis proposal threshold.

\section{Keywords} \\ cross, preparing, doctoral, proposal, threshold:, research, case, students, study, two, international

\section{Disciplines} \\ Education | Social and Behavioral Sciences

\section{Publication Details} \\ Chatterjee-Padmanabhan, M. \& Nielsen, W. (2018). Preparing to cross the research proposal threshold: A \\ case study of two international doctoral students. Innovations in Education and Teaching International, 55 \\ (4), 417-424.
}


Preparing to cross the research proposal threshold: A case study of two international doctoral students

Dr Meeta Chatterjee-Padmanabhan

Dr Wendy Nielsen

University of Wollongong

Wollongong, New South Wales, Australia

Corresponding Author:

Dr Wendy Nielsen

wnielsen@uow.edu.au

phone: +61242214569

School of Education, University of Wollongong

Wollongong, NSW, Australia, 2522

We would like to acknowledge and thank the doctoral candidates who participated in this research.

Their willingness to share their perspectives enables us to better serve them and others who will follow them as doctoral students in our programs. We also thank the very helpful comments from the anonymous reviewers whose suggestions have sharpened and focused the paper. 
Crossing the Research Proposal Threshold 

students

\author{
Abstract \\ This paper presents a study of two international doctoral students' perspectives on preparing \\ to formally present the thesis proposal, which we conceptualize as a threshold in the $\mathrm{PhD}$ \\ journey. They participated in a thesis writing group (TWG) that aimed to support \\ international doctoral students to develop aspects of their scholarship in the early stages of \\ their candidature. The case students reported feeling 'stuck' before joining the thesis writing \\ group run by the authors. After the writing group experience, they reported that they had \\ gained confidence and developed the skills and knowledge required to prepare for their \\ proposal presentation. Their perspectives were gathered through semi-structured interviews \\ that were analysed using the conceptual framework of threshold concepts for doctoral \\ learning. This small-scale study suggests that the collegial support provided by a TWG can \\ be a powerful pedagogy enabling doctoral scholars to confidently negotiate crossing the \\ thesis proposal threshold.
}

Key words: doctoral education; thesis proposal writing; threshold concepts; international students; academic writing; early $\mathrm{PhD}$ candidates

\title{
Introduction
}

Universities in Australia and around the world are increasingly seeking to grow their doctoral programs through admitting international doctoral students. Strategic aims at the university level seek to "Diversify the source and mix of international on-shore student enrolments" and "Assure research impact... at local, national and international levels" (University of Wollongong, 2015, p. 2). Developing a vibrant doctoral student population and community is key to these strategic directions.

International doctoral students often arrive in Australia to study in a second (or third) language, which means that their English language and communicative competence needs development to a sufficient academic and scholarly standard. Beginning a doctoral journey thus involves learning the language of the discipline, the disciplinary genres and for international students, the content of the subject in English. Further, in Australia, Higher Degree Research (HDR) students typically take only a minimal number of courses or subjects, which is where 
Crossing the Research Proposal Threshold

writing and communication skill could develop. Even structured writing programs may provide insufficient emphasis on the communicative purposes of writing (Bastalich 2011). Thus, international students writing in English as an Additional Language (EAL) may have had limited opportunities to develop their research and writing capacities in English which could be a major obstacle to becoming independent doctoral scholars. Where HDR students take limited coursework in their programs, writing support becomes a role for the supervisory team. However, as McWilliam and Singh (2002) argue, the traditional supervisor-supervisee 'academic apprentice-to-disciplinary mentor' relationship is insufficient preparation for doctoral research and writing. And, as Woodward-Kron (2007) suggests, '[S]upervisors may not have the skills to advise on language and discourse organisation issues, nor may they have the skills of making the valued writing requirements of the discipline explicit to the student' (p. 254). Thus, there is a need to supplement the supervisor-supervisee relationship with other forms of doctoral pedagogy.

The current research is grounded in this contemporary university context, where increasingly, international students are challenged to quickly develop writing proficiency perhaps in the absence of coursework or formal feedback on writing from supervisors. Thus, our interest is in developing mechanisms to support doctoral student writing outside the formal structures of coursework or supervision, particularly in the early stages of the doctoral student journey when preparing the research proposal. We ask the research question: What are international students' perspectives on developing the research proposal presentation in the context of a thesis writing group?

\section{Literature Review}

Research in the area of doctoral education has pointed to a 'common absence of curriculum' (Aitchison \& Lee, 2006, p. 266). The absence of a curriculum extends to writing at the doctoral level (Cotterall, 2011; Kamler \& Thomson, 2006). Thesis writing circles are emerging as a popular pedagogic intervention for doctoral writers in response to the need to create a social space (Guerin, Xavis, Doda, Gillam, Larg, Luckner et al., 2013; Li \& Vandermensbrugge, 2011; Mantai, 2015) that can provide benefits such as mutual support, enhanced confidence and a sense of belonging to a scholarly community (Guerin, 2014). Enacting roles of both audience and writer within the supportive scaffolding potentially offered by thesis writing circles fosters formal and informal learning about writing (Aitchison, 2003; Aitchison \& Lee, 2006; Boud \& Lee, 2005; Lee \& Boud, 2003). Thesis writing circles can thus 'horizontalise' pedagogy (Boud \& Lee, 2005), complementing the relationship between supervisor and supervisee and perhaps, mitigating the power imbalance in the supervisory relationship. There is thus a growing agreement that writers' 
groups or thesis writing circles are beneficial to doctoral writers because they are flexible in nature and offer an important connection to a community. However, the largely informal and unstructured nature of the pedagogy can be confusing to doctoral students who are unfamiliar with it (Haas, 2014). To minimize confusion, we therefore sought to develop a thesis writing group (TWG) as a form of horizontalising pedagogy to support international doctoral students. We framed the writing group activities around threshold concepts in doctoral work related to early stages of preparing the research proposal.

\section{Threshold Concepts: A Conceptual Framework}

There is a lively and growing body of literature on threshold concepts in doctoral education that builds on what Meyer and Land (2006) proposed as a series of characteristics of successful learning in an undergraduate program. Meyer and Land convincingly argued that the mastery of certain concepts marked distinctive learning that is transformative because a learner's views of learning and the self as a learner are changed in the process of learning; integrative as disparate aspects of learning begin to make sense; irreversible because once understood, they are not likely to be reversed or unlearnt; bounded since each concept explains specific/related aspects of the whole, but does not constitute the whole; and, troublesome because the new learning presents challenges.

Kiley (2009) appropriates the threshold concepts to represent core learning challenges in the doctoral context as doctoral students progress through research training and writing the dissertation (see also Kiley \& Wisker, 2009). The threshold concepts or core learning challenges in doctoral work identified by Kiley and colleagues include: (1) argument/thesis as a concept; (2) concept of theory; (3) concept of framework; (4) concept of knowledge creation; (5) concept of analysis and interpretation; and, (6) concept of research paradigms. In a recent study on threshold concepts in doctoral writing, Wisker (2015) argued that conceptual thresholds are crossed when 'learning leaps' or breakthroughs are evident in students' work. Further, key facets of doctoral writing and research represent important thresholds in becoming a scholar: personal ownership over the process and coming to understand the notion of contribution that one's scholarship makes to disciplinary knowledge. Trafford and Leshem (2009) proposed the concept of 'doctorateness' to describe both the doing and achievement of a doctorate. Drawing on Meyer and Land's (2006) notion of threshold concepts, Trafford and Leshem (2009) suggest that not knowing what to do or how to do it is a frequent 'blockage' for doctoral students. For multilingual writers writing in EAL in Anglophone universities, there are added challenges, especially in the initial stages of the candidature. 


\section{The Thesis Proposal}

Presenting a thesis proposal or the 'confirmation of candidature' rite of passage is a distinct milestone in the first year of the doctoral journey in Australia. To gain admission to the doctoral program, candidates submit a preliminary thesis proposal as part of the application for admission. The purpose of the document is to express an interest in an area of study, seek a supervisor or supervisors and possibly, apply for a scholarship. The proposal is not expected to be fully developed at the point of admission. Within a year of candidature, however, a fairly comprehensive and scholarly document needs to be produced that outlines the research aims/ questions, the literature review, the theoretical framework and methodology. This is formally presented to an audience of experts from the faculty and a committee that scrutinizes the proposal for its researchability. In short, doctoral scholars have to forecast a provisional view of their research in the proposal presentation and demonstrate an understanding of aspects of the doctoral work and the processes involved early in their doctoral studies. The thesis proposal thus represents a 'learning leap' (Wisker, Kiley, \& Aiston, 2006) that is executed at a critical period of the doctoral program.

\section{The Thesis Writing Group}

We convened a thesis writing group (TWG) for the purpose of supporting the preparations for presenting the proposal. The TWG was designed to help international doctoral students in the School of Education develop threshold concepts (Kiley \& Wisker, 2009) relevant to the thesis proposal stage. We aimed to build from the official structures already in place to support all doctoral students and Figure 1 summarises the activities for the TWG meetings. In the current study, we explore doctoral student perspectives on the TWG series devoted to writing parts of the literature review, theoretical framework, methodology or whichever part of the thesis proposal seemed problematic to them.

\section{INSERT FIGURE 1 ABOUT HERE}

International doctoral students who were within six months of presenting their proposals were invited to attend the TWG meetings. We held the six-session series over a two-week period in January 2014. Due to other commitments, not all students attended all meetings. The group thus included 2-4 doctoral students in each session. During each meeting, the authors led discussions about the particular aspect of the proposal document, reviewing criteria and expectations, and then attendees shared current versions of their documents in a collective review session. Each session 
Crossing the Research Proposal Threshold

lasted 1.5 hours, was guided by the two authors and provided opportunities to practice seeking and offering focused feedback.

\section{Methods}

This research is a case study of two doctoral students who participated in TWG meetings although neither of these students attended all six of the meetings. Semi-structured interviews were held with the two case students after the last meeting of the TWG. Figure 2 presents the semi-structured interview protocol. Interviews lasted up to one hour, and were audio-recorded and transcribed verbatim. Field notes and records from planning sessions and post-meeting debriefing sessions between the two authors supplemented the interview data. Pseudonyms are used throughout.

\section{INSERT FIGURE 2 ABOUT HERE}

\section{Participants}

The two doctoral scholars at the center of this case study had begun their doctoral studies in 2013, one year before the TWG meetings. Prior to the workshop series, they had successfully completed the required coursework elements for their $\mathrm{PhD}$ programs which included a subject devoted to developing the thesis proposal. 'Nadine' came from a Middle Eastern country where she had completed a coursework Masters degree in a related field of education before doing a second Masters degree at a different Australian university. She worked as an academic at a national university in her home country and had been supported to undertake doctoral studies at an Anglophone university. 'Sally' was also a university lecturer in her home country in Asia that had undergone significant educational reform over the last 10 years. One of the reforms supported university academics to earn $\mathrm{PhD}$ credentials at Anglophone universities. Both Nadine and Sally chose Australian universities because of the alignment between their research interests and academic staff expertise at the University of Wollongong.

\section{Results and Reflections}

A number of themes emerged from the participants' responses during the interviews. Some of the points referred to technical aspects of the TWG such as the timing of the sessions, while other responses related to the doctoral experience generally or scholarly writing in English as an Additional Language (EAL). It is interesting that some responses related to the larger threshold concepts such as 'doctorateness' and others related to specific concepts such as critical evaluation of literature and sense of self as a contributor to knowledge. Both case students expressed a primary 
Crossing the Research Proposal Threshold

motivation to improve their research writing. This was reflected in Sally's comment about why she attended the TWG meetings: 'As an international student I do have the problem about writing, so I [wanted to] attend the workshop because I wanted to improve my writing, especially academic writing'.

\section{'I am struggling more and more in order to survive'}

Working through the stages of proposal development, arguably, moves candidates from a state of not knowing to knowing. While the case students had both completed the required coursework that focused on developing a research proposal and further, had worked with their supervisory team for an additional six months at the time of the TWG meetings, they remained uncertain about what 'doctorateness' or doing a PhD meant. During the interview, Nadine expressed her anxieties about the transition from coursework to research:

In my Masters for example, I look at what the lecturer asked me to do in the assignments and I have some procedures to follow. But at the beginning of my $\mathrm{PhD}$, my supervisor asked me: "[what] does the PhD look like?" I said it's like a deep pool and you are struggling not to sink. I'm going down and down. I am struggling more and more in order to survive.

The metaphor of drowning captures a real fear for EAL doctoral students as they wrestle with uncertainties in the early stages of their doctoral work. The complex task of decoding the implicit conventions of scholarly writing in a new educational context and understanding the tacit expectations can be overwhelming. Paradoxically, an implicit expectation of doctoral education is a high level of independence. Nadine noted: 'I had some doubts about whether the organization of the whole proposal is on the right track'. Further, she felt that this was work for her to do outside the supervisory relationship: 'Sometimes you cannot ask those questions from your supervisors; you have to deal with those things by yourself'. She is clearly aware of the tension between becoming an independent scholar and the need to seek answers to troublesome questions. From Nadine's response, it is evident that there is a need for forms of pedagogy that enable transition from not knowing to becoming an independent scholar and researcher outside the supervisory relationship. Guiding students over the threshold by explicitly engaging with the obviously perplexing question, 'What does a $\mathrm{PhD}$ look like?' or the notion of 'doctorateness' is critical. By making space for discussions in TWG sessions some light can be shed on the troublesome intersection of research, writing and disciplinary knowledge that baffles writers when preparing a thesis proposal. 
Crossing the Research Proposal Threshold

\section{Critical appraisal of the literature: Troublesome learning}

Developing the skills needed to critically engage with research literature and positioning one's own research in the disciplinary field are challenges faced by most doctoral students. Nadine commented on this challenge:

At the beginning the problem we have is about the reading: what to read and how to read it. We have a problem and for example I make a table. I write the summary and...write some notes about criticizing or finding the strong and weak points of that article. But it is difficult. How to find this when I [can't] see [it] myself? How can I criticize the person who is expert in that area?

Nadine is aware of the limitations of her own skills and knowledge, and further, questions the legitimacy of expressing a critique of an author who is an 'expert in that area'. During the proposal writing stage and beyond, doctoral students are expected to develop their own scholarly voice through interacting with the research literature. Nadine felt defeated, 'You read a lot and you think that you know a lot but those things are scattered in your mind; you don't have any link between them'. This is partly because having read in other languages, international doctoral scholars using EAL may only be beginning to gain a sense of the disciplinary conversations in their chosen discipline area in English and therefore, find it difficult to position themselves in relation to literature in the field. Critiquing the literature remains a troublesome threshold for many doctoral writers. Explicit strategies to review research and present it in scholarly writing can be embedded in TWGs and will be discussed below.

\section{'My contribution can help them'}

A significant, irreversible difference that the TWG made for Sally was a positive sense of self. Hesitance to share one's work with others was an initial obstacle in the TWG. A key activity during the TWG was reviewing each other's writing. We positioned this activity as part of each of the TWG sessions in order to facilitate developing the vital skills of giving and receiving feedback as noted in the January, 2014 invitation to the TWG: 'students are encouraged to bring their work to the sessions to give and receive feedback so that they can improve their work in a friendly learning atmosphere'. In the TWG, receiving and giving feedback was modeled and encouraged as a mechanism for engaging with a scholarly community.

Sally expressed an understanding of the significance of giving and receiving feedback as a scholarly activity. During the interview, we asked: 'What do you think other students might have learned from you?' She responded: 
Crossing the Research Proposal Threshold

I have a chance to listen to them and not really correct their work, but give them

suggestions, give them some ideas. I hope what I contribute [and that] my contribution can

help them, because at the time, some students have learned from my work.

An important dimension of learning to be an independent scholar is giving and receiving feedback from others. Sally felt empowered by the fact that she could offer relevant feedback to her colleagues, and because she felt that she had something to contribute to the community, her confidence grew. Getting and giving feedback on work-in-progress helps develop not only strategies and tools, but also a sense of self as a contributing member of the scholarly community. Troublesome as it is, this is an important threshold crossing, and thus gaining a sense of being a doctoral scholar becomes irreversible. We were pleased to see Sally cross this threshold through participating in the TWG.

\section{'The theoretical framework and methodology...it is really blurry'}

Doctoral students must demonstrate a beginning mastery over each discrete aspect of the thesis including the literature review, the theoretical framework and the methodology and furthermore, be able to see the interconnection between the various parts. Nadine reported difficulties:

I think theoretical framework and especially methodology is the part that we have problems [with] because in our proposal we have something in our mind, it is really blurry. We don't know whether it works or not. The methodology is the part that we are struggling; most of the students are struggling about that.

Nadine was on the threshold of becoming an independent researcher; she had second-hand experience of comprehending research from conducting the literature review. However, not having undertaken research before, she was challenged by the idea of developing and conducting her own research. Others shared similar challenges during the TWG meetings, even as they tentatively began to see connections between their provisionally learnt ideas in creating a coherent document and their advancing notions of self as researcher. In Nadine's words, 'developing the proposal it was very troublesome because you have some ideas, again your supervisor asks you to make links between those ideas. It was very difficult finding those links and being critical'. Finding links and being critical are two areas that pose challenges as doctoral students begin to integrate the literature in the field, the theories they study and make decisions for appropriate research designs.

\section{Discussion}

The thesis proposal presentation is a unique 'rite of passage' in which doctoral scholars demonstrate their readiness to cross the threshold from not knowing to knowing, from being Masters students to 
being doctoral scholars preparing to make an original contribution to their chosen fields.

Confidently positioning one's research in a field that is still only half understood is normal in the first year of candidature for both native speakers of English and multilingual international students when one is not yet socialized into the disciplinary area. Learning to analyse and synthesise the literature in one's discipline is an integral part of research training because of the need to integrate this knowledge meaningfully. The word 'link' often emerged as a key word from interviews in the current study. Finding connections and links in the body of literature is a threshold that doctoral students struggle to cross. Taking a stance and developing a voice in the early stages in relation to the literature and finding evidence to support one's argument are skills that cannot be learned mechanistically, but rather, must be developed through gaining familiarity with the discourse community in the disciplinary area (Wisker, 2015). The complex task of beginning research in a newly acquired language, understanding the tacit conventions of disciplinary writing and projecting an appropriate identity is daunting (Cotterall, 2011; Kamler \& Thomson, 2006). The TWG is an opportunity for students to clearly realise this.

The doctoral threshold concepts outlined by Trafford and Leshem (2009), Kiley (2009) and Kiley and Wisker (2009) represent a powerful way to conceive the key dimensions of doctoral learning. Terminology slipperiness notwithstanding, we see great value in persisting with further refining and theorizing threshold concepts in the context of doctoral education and writing. For example, Trafford and Leshem (2009) situate 'synergy and therefore' at the centre of doctoral learning and point to two of the most central competencies of doctoral writers: the ability to pull together and link multiple ideas, concepts and texts (e.g. synergy); and, the ability to provide solid justification for choices and arguments throughout a thesis ('therefore'). While grammatically awkward, the phrase 'synergy and therefore', encapsulates the essence of the threshold concepts of linking and justification that are, from our empirical study, a crucial and ongoing challenge for international doctoral scholars.

We have learnt from running the TWG meetings that careful 'amalgamation of a variety of developmental opportunities' (Mantai, 2015, p. 12) is essential in the proposal writing stage of doctoral studies. The TWG provided a social environment where scholarly engagement was modeled and doctoral students could practice giving and receiving feedback, while learning from others. Aitchison and Lee (2006) forcefully argue that TWGs offer occasions where doctoral scholars begin to recognise

[w] hat it looks like and feels like to offer a critique, make a claim, exert an authoritative stance, advance an argument, reflect, position oneself in a text or a field, assert a voice and enter explicitly into the exchange over particular texts. These matters can become subjects of explicit discussion and negotiation as members' texts are examined within groups. 
(p. 273)

This social dimension of doctoral writing became evident to the participants in the current study as they moved away from static or discrete discussions about parts of the thesis proposal to the integrative work required to produce a coherent document. Becoming part of a scholarly community also enabled participants to transition from being an individual knower (and learner) to becoming a contributing member. Our experience with the TWG confirms Wisker's (2015) suggestion that engaging with others' writing helps to develop confidence with one's own scholarly voice.

\section{Limitations and further studies}

Although the in-depth interviews captured crucial aspects of the participants' doctoral experience, linguistic challenges that international students writing in EAL face in mastering threshold concepts were not comprehensively explored. There is clearly scope for further investigation.

\section{Conclusion}

This research included a small case study that explored the experiences of two international students after a series of thesis writing group meetings where they were supported to develop their proposal presentations. The threshold concepts helped us to understand the thesis proposal as troublesome, particularly for doctoral scholars writing in EAL. We have learnt that the notion of 'doctorateness' is problematic in the early stages and thus needs explicit demystification. In future, we aim to embed threshold concepts such as critical evaluation in the pedagogic space that the TWG offers, and further, emphasise and model 'synergy and therefore'. We also aim to develop the 'horizontalising' potential of the TWG in order to foster the skills and competencies that international EAL scholars might need to transition from their previous educational contexts to their doctoral studies in an Anglophone country.

\section{References}

Aitchison, C. (2003). Thesis writing circles. Hong Kong Journal of Applied Linguistics, 8(20), 97115.

Aitchison, C., \& Lee, A. (2006). Researching writing: Problems and pedagogies. Teaching in Higher Education, 11(3), 265-278.

Bastalich, W. (2011). Beyond the local/general divide: English for academic purposes and process approaches to cross disciplinary, doctoral writing support. HERDSA News, 30(4), 449-462. 
Boud, D., \& Lee A. (2005). Peer learning as pedagogic discourse for research education. Studies in Higher Education, 30(5), 501-515.

Cotterall, S. (2011). Doctoral students writing: Where's the pedagogy? Teaching in Higher Education, 16(4), 413-425.

Guerin, C. (2014). The gift of writing groups: Critique, community and confidence. In C. Aitchison \& C. Guerin (Eds.), Writing groups for doctoral education and beyond: Innovations in practice and theory (pp. 128-141). London: Routledge.

Guerin, C., Xafis, V., Doda, D. V., Gillam, M. H., Larg, A. J., Luckner, H. et al. (2013). Diversity in collaborative research communities: A multicultural, multidisciplinary thesis writing group in public health. Studies in Continuing Education, 35(1), 65-81.

Haas, S. (2014). 'Pick-n-mix: A typology of writers' groups. In C. Aitchison \& C. Guerin (Eds.), Writing groups for doctoral education and beyond: Innovations in practice and theory (pp. 30-47). London: Routledge.

Kamler, B., \& Thomson, P. (2006). Helping doctoral students write: Pedagogies for supervision. New York, NY: Routledge.

Kiley, M. (2009). Identifying threshold concepts and proposing strategies to support doctoral candidates. Innovations in Education and Teaching International, 43(3), 293-304.

Kiley, M., \& Wisker, G. (2009). Threshold concepts in research education and evidence of threshold crossing. Higher Education Research and Development, 28, 431-441.

Lee, A., \& Boud, D. (2003). Writing groups, change and academic identity: Research development as local practice. Studies in Higher Education, 28(2), 187-200.

Li, L. Y., \& Vandermensbrugge, J. (2011). Supporting the thesis writing process of international research students through an on-going writing group. Innovations in Education and Teaching International, 48(2), 195-205.

Mantai, L. (2015). Feeling like a researcher: Experiences of early doctoral students in Australia. Studies in Higher Education. Online 11 August, 2015. DOI: 10.1080/03075079.2015.1067603

McWilliam, E., \& Singh, P. (2002). Towards a research training curriculum: What, why, how, who? Australian Educational Research, 29(3), 4-18.

Meyer, J., \& Land, R. (Eds.) (2006). Overcoming barriers to student understanding: Threshold concepts and troublesome knowledge. Abington, UK: Routledge.

Trafford. V., \& Leshem, S. (2009). Doctorateness as a threshold concept. Innovations in Education and Teaching International, 46(3), 305-316. 
Crossing the Research Proposal Threshold

University of Wollongong. (2015). Strategic Plan 2013-2018. Office of Strategic Plan and Quality, University of Wollongong.

Wisker, G. (2015). Developing doctoral authors: Engaging with theoretical perspectives through literature review. Innovations in Education and Teaching International, 52(1), 64-74.

Wisker, G., Kiley M., \& Aiston, S. (2006). Making the learning leap: Research students crossing conceptual thresholds. In M. Kiley \& G. Mullins (Eds.), Quality in postgraduate research: Knowledge creation in testing times (pp. 195-201). Canberra, ACT: CEDAM.

Woodward-Kron, R. (2007). Negotiating meanings and scaffolding learning: Writing support for non-English speaking background Postgraduate Students. Higher Education Research and Development, 26(3), 253-268. 